\title{
Prospective Implant Placement Following Traumatic Loss of Anterior Teeth in a Growing patient and Anticipation of Residual Growth
}

\author{
Jan Tetsch ${ }^{1 *}$, and Felix Tetsch ${ }^{2}$ \\ ${ }^{1}$ med. dent, M.Sc., Scharnhorststr, Germany \\ ${ }^{2}$ cand. Med. Dent, Scharnhorststr, Germany
}

*Corresponding author: Jan Tetsch, Med. dent, M.Sc., Scharnhorststr, Germany, Tel: +49 251-53 24 15; E-mail: jantetsch@t-online.de

Received: 13 Jun, 2020 | Accepted: 23 Jun, 2020 | Published: 30 Jun, 2020

Citation: Tetsch J, Tetsch F (2020) Prospective Implant Placement Following Traumatic Loss of Anterior Teeth in a Growing patient and Anticipation of Residual Growth. Int J Dent Oral Health 6(5): dx.doi.org/10.16966/2378-7090.329

Copyright: (c) 2020 Tetsch J, et al. This is an open-access article distributed under the terms of the Creative Commons Attribution License, which permits unrestricted use, distribution, and reproduction in any medium, provided the original author and source are credited.

\section{Summary}

15 years ago, an interdisciplinary concept, covering the controversial topic of implants in growing patients, was developed which aimed at producing early positive functional and aesthetic results in the upper anterior region of adolescents. Following anterior tooth trauma and in cases of agenesis, extensive orthodontic diagnostic and therapeutic pretreatment was first performed according to modifications of the accepted guidelines for adults followed by implant placement anticipating expected jaw growth. The objective is to prevent inactivity atrophy following tooth loss and achieve symmetry to the contralateral tooth once growth has been concluded. The concept encompasses modifications to the prosthetic restoration. 179 implants were placed in the upper anterior regions of patients aged between 12 and 17 years. The results obtained during the growth period were checked every six months and evaluated using standardised photo documentation. To date, the examinations up to conclusion of growth have been carried out, evaluated and published for 67 implants.

The outcome of the photometric analysis indicates that, in comparison to the corresponding teeth during the growth period, compromises in the aesthetics of the emergence profile must be accepted but that, in all cases, once jaw growth has been concluded, the white and pink aesthetics exhibit no significant differences to the corresponding teeth.

Keywords: Dental implants during growth; White and pink aesthetics (WES/PES); Photometric analysis; Ageneses; Traumatic tooth loss; Psychosocial development

\section{Introduction and Problem Definition}

Agenesis with a prevalence of $5.5 \%$ of the entire population together with primary or secondary irreversible tooth loss following trauma are the most prevalent causes of gaps between upper anteriors in children and adolescents [1]. These missing teeth result in a range of consequences, which, in addition to limited function, include development of the alveolar process, aesthetics and the psychosocial development of the children or adolescent patients.

The limits or phases of body length growth have been studied thoroughly and clearly defined. There is no clear conclusion to alveolar process growth. The alveolar process grows via desmal ossification (no preliminary cartilage stage). During vertical facial height development, the maxilla drifts away from the base of the skull independent of the teeth in that material is resorped from the cranial aspect and built up caudially [2]. Apart from the drift, further vertical growth takes place as a result of the teeth erupting to the occlusal plane. On their way, the teeth in the transitional dentition transport their own bone with them to form the final height and width of the alveolar process bone. Cases with dental aplasia lack this physiological process thus leading to the typical rudimentary monocortically formed alveolar process. In case of solitary agenesis where the gap is narrow, e.g. an upper lateral incisor, the height of the alveolar process appears to be influenced positively by the growth of the adjacent teeth. However, the width is always monocortical and with reduced blood circulation. One speaks of hypoplasia of the alveolar process. Hypoplasia must not be confused with atrophy. Hypoplasia is a genetically-programmed condition which develops without being influenced by growth of the teeth and persists in the poor initial findings. Atrophy is a loss of substance from a primarily, regularly formed alveolar process. The initial condition is good but it worsens due to lack of function according to the stages of atrophy $[3,4]$. Due to atrophy taking place rapidly where teeth have been lost, the time window for therapy is limited whereas in cases of agenesis it is less restricted because the prerequisites do not deteriorate.

The various types of conservative treatment are often unsatisfactory and incapable of halting the problem of advancing atrophy due to lack of functioning in the affected region [5,2].

Provision of conventional and implant-borne prosthetic restorations prior to completion of jaw growth involves risk as the pertinent jaw sections do not follow the complex three-dimensional 
developments in the jaw and alveolar process $[1,6,7]$. This may result in considerable functional and aesthetic disadvantages. In their retrospective studies over a period of several years, Westwood RM, et al. [8] as well as Bernard JP, et al. [9] observed infraclusion of implantborne crowns. To make matters worse, individual growth is difficult to estimate. Due to these risks, it is recommended that implants not be placed before the age of 19 [10-12]. In contrast, the morphological and psychosocial aspects of early implantation are positive.

Studies by Björk A, et al. [13] showed that transverse growth of the maxilla begins with widening of the base of the skull and growth in the region of the sutura medialis during early childhood. This process is virtually complete once puberty commences. Implant placement before the age of [13] may lead to a diastema [14,15]. Sagittal growth causes the maxilla to develop downwards and forwards and may result in malpositioning of previously placed implants. Vertical growth involves changes to the orbita, maxillary sinus and nasal cavity and is completed last [16]. It is heavily influenced by the geneticallydetermined facial type (long or short). Implants placed before vertical growth has been completed may end up in the maxillary sinus or nasal cavity [8]. A further problem is that growth takes place individually in very different phases influenced by orthodontic treatment and muscle activity (e.g. masseter muscle). Particularly powerful growth episodes are to be anticipated during puberty, i.e. the patient's age is not the sole criteria to be considered when deciding pro or contra implant placement. Intensive planning and interdisciplinary cooperation are required in order to determine the correct moment in time $[17,18]$. In cases with traumatic tooth loss or aplasia placement of implant-borne restorations is controversial during growth due to the high number of aesthetic failures. For this reason, placement of implant-borne restorations in cases with traumatic tooth loss is usually postponed until the growth period is over. If long periods of time elapse before aesthetically-sensitive areas are treated many lasting problems may result which may possibly be prevented by early implant placement.

The contradiction in treatment following tooth loss is based entirely on the patient's age. Whereas in adults with or pending tooth loss the trend is toward early or even immediate implant placement in order to preserve structures and prevent hard and soft tissue atrophy, a totally contrary approach is taken for children and adolescents. Certain schools of thought recommend avoiding implant placement until the age of 16 or even 30 depending on the sex. In case of early tooth loss, a long-term temporary restoration is suggested and functional nonloading of the bone and soft tissue with resulting atrophy taken into account. In addition to the operation planned for the future, which may not be carried out until years later, extensive augmentation of the hard and soft tissues is frequently required which may produce unsatisfactory results. The morphological problems are often accompanied by a psychic component which can only be partially gauged and may impede the child's development to adulthood.

Implant positioning anticipating residual growth was developed years ago in Münster, Germany. During adolescence from the age of 12 and following the pubertal growth episode and custom, interdisciplinary diagnostics the implant is placed according to the growth pattern and ensuring that the emergence profile is symmetrical to the contralateral tooth. Implant positioning during growth is diagnosed and determined differently than with adults. In 2004 Belser $\mathrm{U}$, et al. [19] described the ideal implant position for adults, modified it in 2018 and to this day it is considered the standard three-dimensional positioning. When placing implants in a growing jaw the rules for implant positioning, with a few modifications, are transferred to adolescents. In addition, the implant position is matched to the growth pattern in order to determine the emergence profile and implant placement angle. In case of clockwise growth, the implant must be placed further toward the palatal aspect as the mid-section of the face and natural teeth develop caudopalatally during the ensuing growth. In case of counter-clockwise growth, as the mid-section of the face in adolescents develops ventrocaudally the implant position must be modified accordingly toward the vestibular aspect.

With adolescents the vertical position is matched to the growth pattern. Following the pubertal growth episode, $3.1 \mathrm{~mm}$ vertical growth may still take place and must be anticipated for the implant position. During therapy, a brachiofacial horizontal growth pattern is advantageous compared to a dolichofacial vertical growth pattern. A brachiofacial growth pattern results in formation of a broad, low face. Thus, vertical growth is lower and, if it only develops in breadth, can resemble the position of implant placement in adults.

A dolichofacial growth pattern forms a narrow, high face. In such cases, there is a high risk of vertical malpositioning if the vertical development of the mid-facial section is due to growth of the residual vital teeth and consequent high vertical growth of the alveolar process which is difficult to predictmetrically. Once placed, the implant has no influence on the growth of the alveolar process and retains its position within this region of the jaw. Placing the implant fixes its position permanently without surgical procedures such as segment osteotomy or distraction osteogenesis. The vertical position appears to be the greatest problem when placing implants in adolescents' jaws. Following the pubertal growth episode, a maximum of $7.9 \mathrm{~mm}$ infraclusion was observed in cases of early implant placement. The metric predictability of how many millimetres of potential growth the alveolar process exhibits in combination with the skeletal growth of the base of the jaw has yet to be defined.

The largest group of facial types is located between the two types of growth and encompasses horizontal and vertical expansion. This facial type is referred to as the mesiofacial type and applies to $70 \%$ of the population.

Prospective positioning of the implant including anticipating the residual growth, takes into account the growth pattern and type. Once growth has been concluded, the emergence profile and prosthetic restoration should correspond to the contralateral tooth. Modifying or remaking the prosthetic restoration during the growth episodes are part of the concept but the position of the implant remains unchanged. Early rehabilitation of adolescent patients is advantageous in that during their development they are provided with a fixed tooth which has a positive effect on their masticatory, speech and personality development.

In order to visualise prospective implant placement including anticipating growth, a patient from our practice will be described. Treatment commenced on17-08-2010 at the age of 11 years, 7 months. Tentative conclusion of therapy: 09-03-2020 at the age of 21 years, 2 months.

On 17-08-2011 a boy aged 11 years, 7 months presented in our practice with trauma of tooth [6]. The clinical and radiological diagnoses indicated pulpal aperta of both pulp horns and a suspected palatal longitudinal fracture. Conservative treatment involving direct pulp capping followed by endodontic procedures was performed in an attempt to retain the tooth and restore its aesthetics as well as masticatory functioning (Figures 1 and 2).

Following recurrent suppuration, on 20-08-2012 the longitudinally fractured tooth [6] was extracted at the age of 13 years, 7 months. To 
prevent atrophy due to inactivity, socket preservation was carried out using Bio-Oss Collagen and autologous bone particles. A double-wing, resin-bonded bridge was then placed temporarily.

Once the orthodontic pre-treatment, diagnostic measures for anticipated growth and growth types had been completed, upon commencement of the lateral atrophy on 25-10-2013 the implant was placed at the age of 14 years, 9 months. Beginning lateral atrophy is the strongest indication that inactivity atrophy is setting in and the latest moment in time for implant placement once the canines have reached their definitive positions. It is an advantage if the pubertal growth episode has already been completed (Figures 3-5).

After an 8-week healing period on 20-12-2013 the implants were recovered and a modifiable crown placed at the age of 14 years, 11 months.

Due to the planned implant position, the marginal region of the crown was designed asymmetrically too short in comparison to the contralateral tooth and exhibited a considerable excess of hard and soft tissue. For the continued growth of the alveolar process-caused by the vital teeth growing toward the occlusal plane-this potential growth was taken into account when planning the emergence profile of the mesiofacial growth pattern of the mid-face (Figures 6 and 7).

A growth episode typical for boys occurred from April to August 2014 between the ages of 16 and 17 years. The patient's body grew 24 $\mathrm{cm}$ in length during this period and the prosthetic restoration was twice adapted to the growth episode and continued to exhibit excess hard and soft tissue around the marginal emergence profile (Figures 8-11). Simultaneously, due to the clockwise growth of the natural teeth toward the palatal aspect, the implant appeared to have been repositioned slightly toward the vestibular aspect.

Up to the age of 20 years the prosthetic restoration was not modified. At the age of 19 years, 2 months, the incisal edge of the crown appeared slightly too short (Figure 12). The patient's body had grown $2 \mathrm{~cm}$ from $183 \mathrm{~cm}$ to $185 \mathrm{~cm}$ and the prosthetic restoration was replaced with a new occlusal screw-retained crown. The excess tissue was used to form the emergence profile symmetrically to the contralateral tooth (Figures 13-16).

The check-up at age 21 years shows the perfectly stable outcome for tooth [6] (Figures 17 and 18).

Figures 19-25 shows clearly the growth over the past years. During placement, the first, third and definitive crowns were secured intraorally in order to visualise the growth. The changes due to growth can be seen clearly in the marginal and incisal regions. For clarification, the crowns were placed on the first and last model, photographed and evaluated metrically. The predicted growth is also clearly visible here.

\section{Discussion and Conclusion}

In case of agenesis or upper anterior tooth loss in children and adolescents, conventional restorations exhibit serious drawbacks and sometimes have negative consequences for the dental and psychosocial development of these young patients $[1,16,20-22]$. One of the serious problems is bone loss in the affected region which often can only be

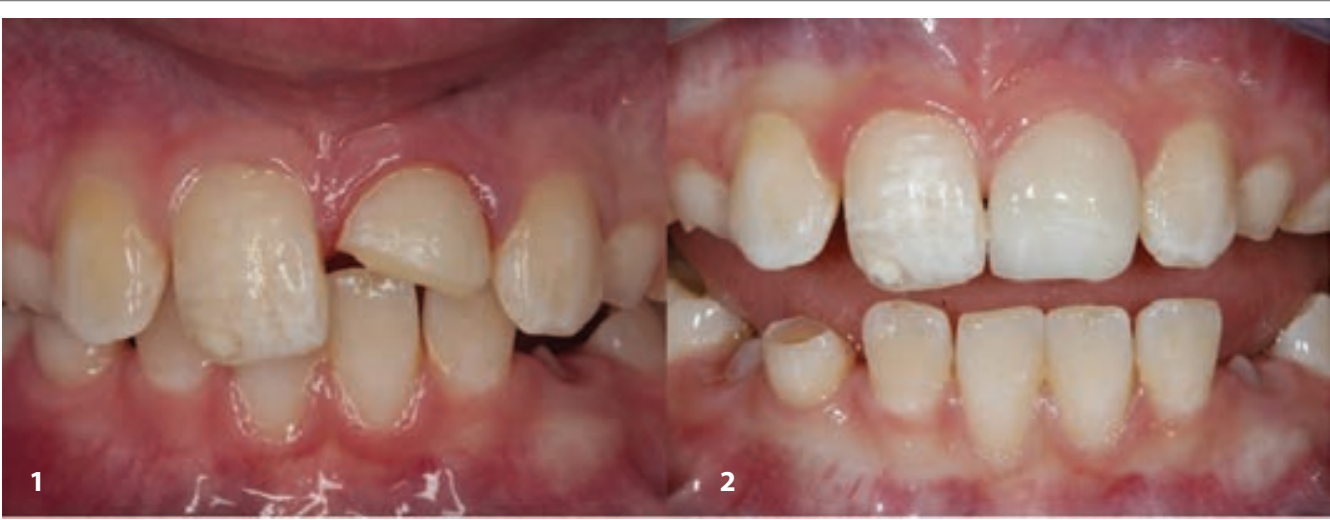

Figure 1 \& 2: Conservative treatment involving direct pulp capping followed by endodontic procedures was performed in an attempt to retain the tooth and restore its aesthetics as well as masticatory functioning.

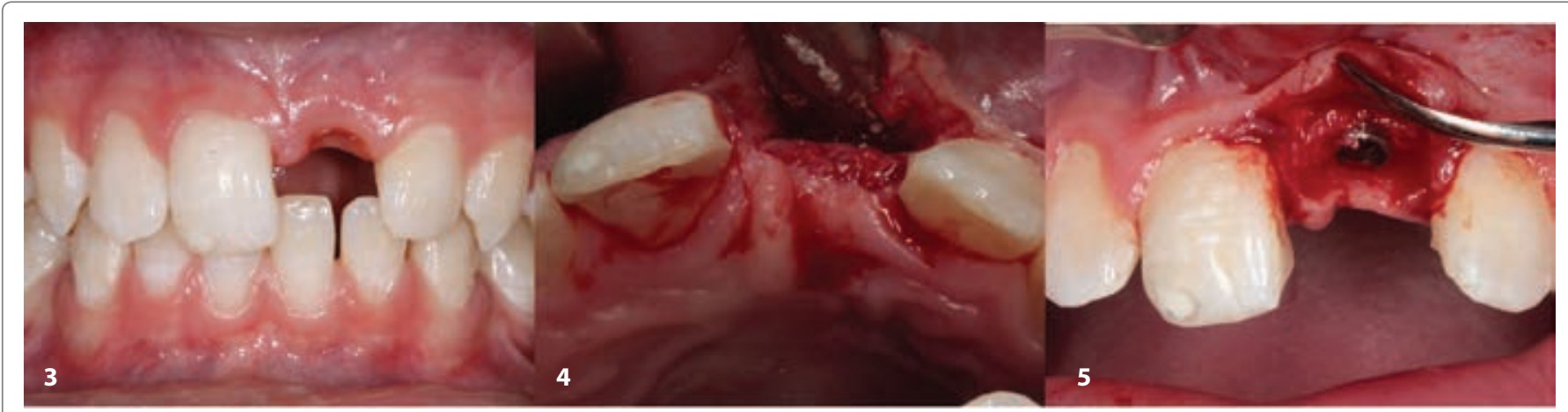

Figure 3-5: An advantage if the pubertal growth episode has already been completed. 


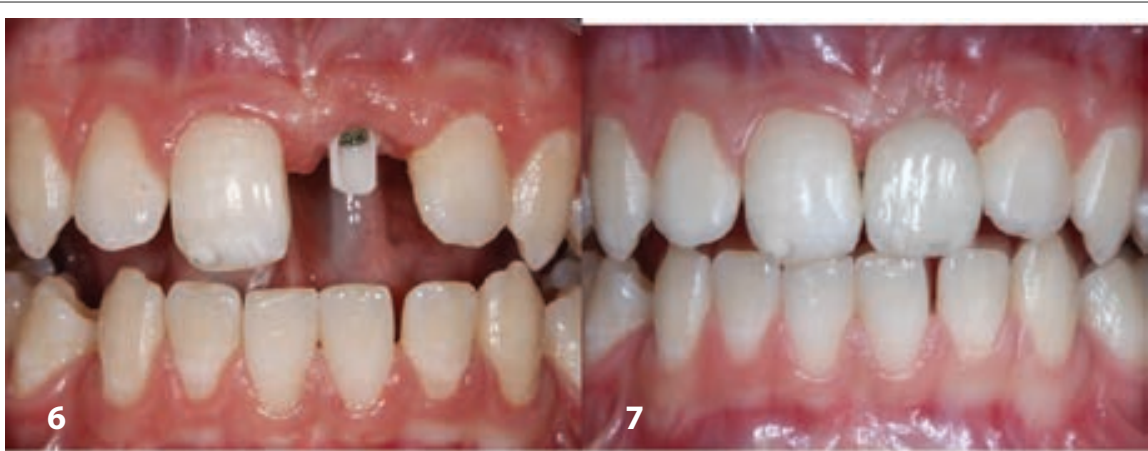

Figure 6 \& 7: Potential growth was taken into account when planning the emergence profile of the mesiofacial growth pattern of the mid-face.
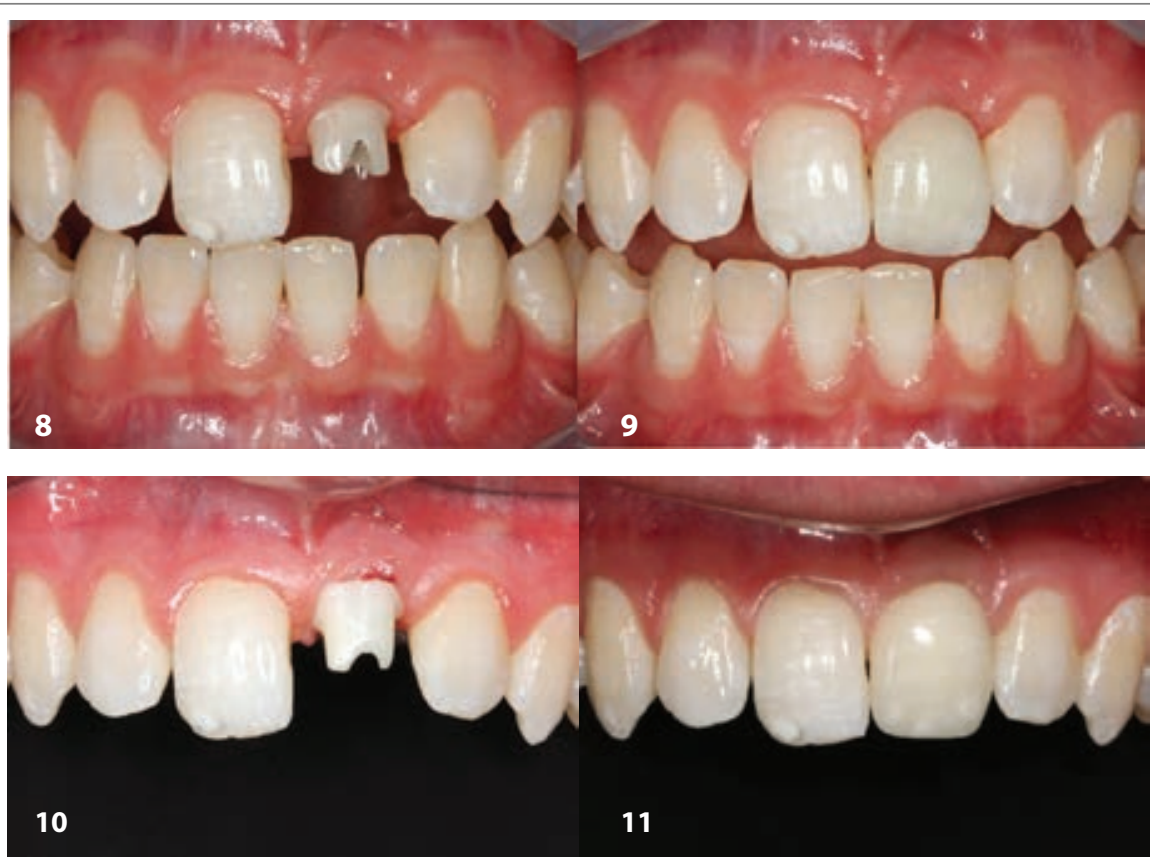

Figure 8-11: The patient's body grew $24 \mathrm{~cm}$ in length during this period and the prosthetic restoration was twice adapted to the growth episode and continued to exhibit excess hard and soft tissue around the marginal emergence profile.

corrected using time-consuming and risky augmentation techniques $[23,24]$. The outcome is often unsatisfactory as loss of hard tissue causes atrophy of the soft tissue. This often leads to loss of attachment on the adjacent tooth which is difficult or impossible to reconstruct. Although early implant placement conserves the bone, considerable risks are involved as the implants do not follow the complex threedimensional development of the jaw and alveolar process $[6,12]$. This may cause considerable disadvantages for the functioning and aesthetics. In their 4-year retrospective study Bernard JP, et al. [9] monitored infraclusion of implant-borne anterior crowns. The survival rate of implants placed before the age of 13 was approx. 20\% higher than in older patients $[5,2]$. The complications were increased by the fact that the growth of individual patients is difficult to estimate-the teeth may drift mesially by up to $5 \mathrm{~mm} \mathrm{9}$. Owing to these risks, it is now recommended that implants not be placed prior to the age of 19 years $[10,6,7]$. In contrast, the morphological and psychosocial aspects of early implant placement are considered positive. The literature increasingly includes reports about implant-borne restorations placed during the growth phase. This applies particularly to patients with oligodontia or anodontia in connection with ectodermal dysplasia or other rare clinical pictures with comparable problems [25-33]. But the data available remains insufficient. According to an analysis by Yap AK, et al. [34] covering 12 studies with 471 patients (one cross-sectional study $(n=52)$, three prospective case studies $(n=197)$, six retrospective case studies $(n=104)$ and two mixed studies $(n=118)$ ) for those patients with ectodermal dysplasia the survival rate is between $88.5 \%$ and $97.6 \%$ (3 studies involving 71 patients) and in case of agenesis with other causes $90 \%$ and $100 \%$ ( 178 patients involved in 5 studies). In one of the studies $(\mathrm{n}=13)$ no difference in the survival rate was determined between the 3 age groups (up to 11 years, 11-18 years, over 18 years). In one of the other studies ( $\mathrm{n}=51$ patients) significantly higher failure rates were determined where the patients were under the age of 18 years. Heuberer S, et al. [33] placed 71 implants in 18 oligodontia patients aged 12.5 years on average. They established a survival rate of $89 \%$ at an average period in situ of 11 years. In an international Delphi study involving 11 internationally experienced teams Klineberg I, et al. [34-36] attempted to establish a consensus for the rehabilitation of children with ectodermal dysplasia. The implant treatment was to be 


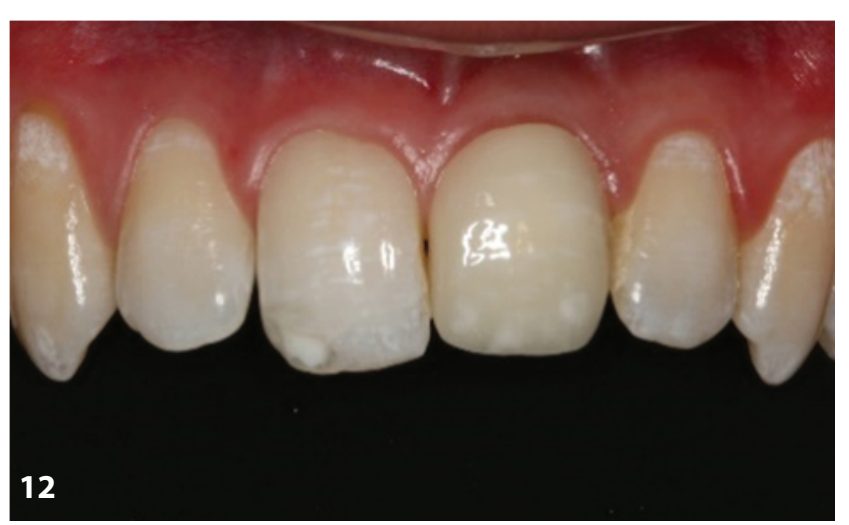

Figure 12: At the age of 19 years, 2 months, the incisal edge of the crown appeared slightly too short.
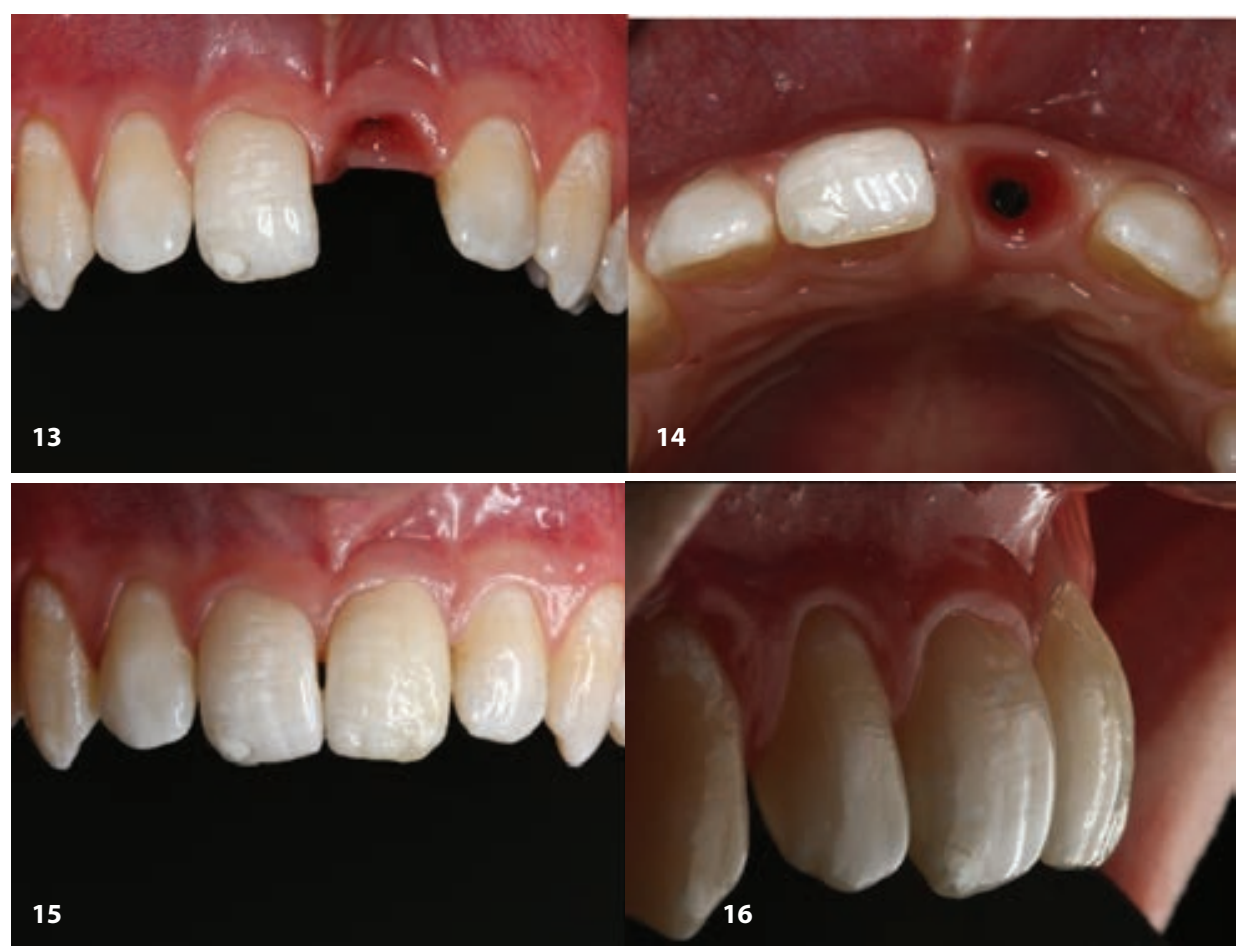

Figure 13-16: The excess tissue was used to form the emergence profile symmetrically to the contralateral tooth.
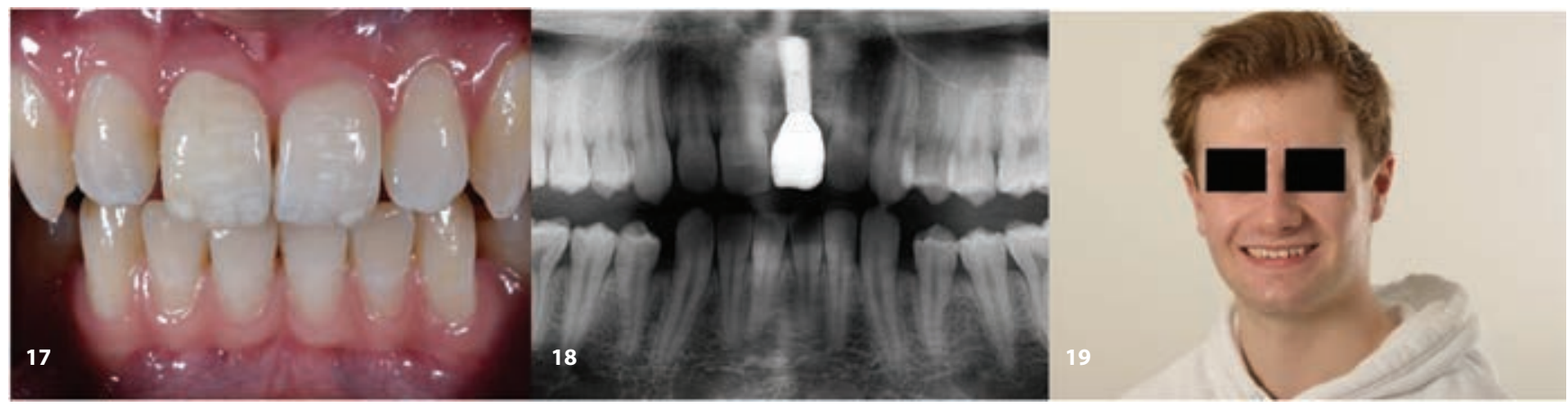

Figure 17-19: The check-up at age 21 years shows the perfectly stable outcome for tooth 21. 


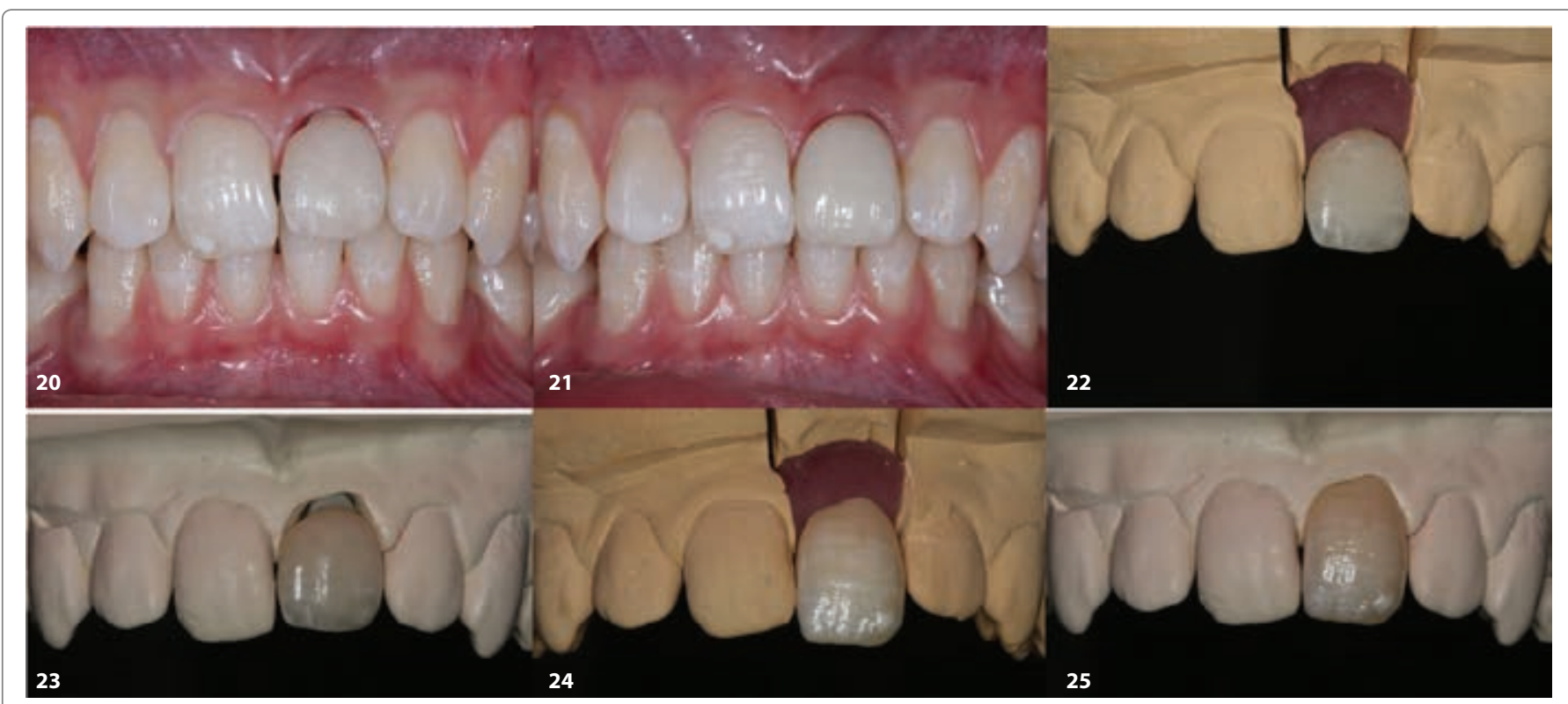

Figure 20-25: The changes due to growth can be seen clearly in the marginal and incisal regions.

carried out according to ethical aspects in the children's best interests as described in the "United Nations Convention on the Rights of the Child" by specially trained and experienced dentists drawn from a multidisciplinary group encompassing the specialist fields of pedodontics, orthodontics, prosthetics and oral surgery. No consensus was agreed upon for the optimum age of patients for implant measures.

The time at which the implant is placed depends on the patient's growth whereby body growth and condition of the dentition play important roles. Decisive is that the specific patient is observedgeneralisation and defining a certain age for patients makes no sense. The therapy depends on the degree of prerequisites for therapy, the time at which the tooth was lost and the outcome of an interdisciplinary analysis of the growth.

In departure from the accepted guidelines for the anterior region $[19,37]$, implants placed during growth must be positioned vertically so as to allow for anticipated growth of the jaw. The anticipated rotation must also be taken into account along the vestibulo-oral axis. Analysis of growth becomes easier and more reliable as age increases. In case of early implant placement, normally only the augmentation procedures described are required. Examining the parents and siblings as well as long-term observation of the specific patient is particularly helpful in determining the position. Following implant placement and until jaw growth is concluded, crowns are fitted which are clinically too short around the margins and the compromised aesthetics accepted. If necessary, during the growth phase the crowns may have to be adapted to the changing conditions several times. In our experience, a favourable moment for placing incisal implants is once the upper canines have been set-up completely.

Prospective implant placement in growing jaws appears to be a possible key to equivalent procedures for adolescent patients with the same indication as for adults. The clinical experience gained with 179 implants placed for this indication is very promising and showed that, even following loss of several incisors, using this procedure the alveolar process can be maintained and long-term favourable aesthetics achieved. It is decisive to make use of all diagnostic, interdisciplinary planning methods and, finally, customised targeted therapy. The implant should be placed as late as possible yet as early as necessary. In this respect, recommendation number 9 of guideline S3 with the AWMF registration number: 083-024 (as of 2016/ valid until December 2021) should be applied analogous to the procedure for traumatic loss of anterior teeth to implant-borne restorations for multiple tooth agenesis and syndromes.

\section{References}

1. Agarwal N, Kumar D, Anand A, Bahetwar SK (2016) Dental implants in children: A multidisciplinary perspective for long-term success. Nat J Maxillofac Surg 7: 122-126.

2. Terheyden $H$, Wüsthoff $F(2015)$ Occlusal rehabilitation in patients with congenitally missing teeth-dental implants, conventional prosthetics, tooth autotransplants, and preservation of deciduous teeth-a systematic review. Int J Implant Dent 30.

3. Cawood JI, Howell RA (1988) A classification of the edentulous jaws. Int J Oral Maxillofac Surg 17: 232-236.

4. Tan WL, Wong TL, Wong MC, Lang NP (2012) A systematic review of post-extractional alveolar hard and soft tissue dimensional changes in humans. Clin Oral Implants Res 23: 1-21.

5. Terheyden H, Tetsch J, Kopp I, Auras S (2016) S3-Leitlinie (Langversion) Zahnimplantatversorgungen bei multiplen Zahnnichtanlagen und Syndromen. AWMF-Registernummer 083-024.

6. Oesterle LJ, Cronin RJ, Ranly DM (1993) Maxillary Implants and the Growing Patient. Int J Oral Maxillofac Implants 8: 377-387.

7. Percinoto C, Vieira AE, Barbieri CM, Melhado FL, Moreira KS (1985) Use of dental implants in children: a literature review. Quintessence Int 32: 381-383.

8. Westwood RM, Duncan JM (1996) Implants in adolescents: A literature review and case reports. Int J Oral Maxillofac Implants 11: 750-755.

9. Bernhard JP, Schatz JP, Christou P, Belser U, Kiliardis S (2004) Longterm vertical changes of the anterior maxillary teeth adjacent to single implants in young and mature adults. A retrospective study. J Clin Periodontol 31: 1024-1028. 
10. Mankani N, Chowdhary R, Patil BA, Nagari E, Madalli P (2014) Osseointegrated dental implants in growing children: a literature review. J Oral Implantol 40: 627-631.

11. Oesterle LJ, Cronin RJ Jr (2000) Adult growth, aging, and the singletooth implant. Int J Oral Maxillofac Implants 15: 252-260.

12. Op Heij DG, Opdebeeck H, van Steenberghe D, Kokich VG, Belser $U$, et al. (2006) Facial development continuous tooth eruption, and mesial drift as compromising factors for implant placement. Int J Oral Maxillofac Implants 21: 867-878.

13. Björk A, Skieller V (1977) Growth of the maxilla in three dimensions as revealed radiographically by the implant method. Br J Orthod 4 : 53-64.

14. Brugnolo E, Mazzocco C, Cordioll G, Majzoub Z (1996) Clinical and radiographic findings following placement of single-tooth implants in young patients-Case reports. Int J Periodontics Restorative Dent 16: 421-433.

15. Ledermann PD, Hassell TM, Hefti AF (1993) Osseointegrated dental implants as alternative therapy to bridge construction or orthodontics in young patients: Seven years of clinical experience. Pediatr Dent 15: 327-333.

16. Cronin RJ Jr, Oesterle LJ (1998) Implantuse in growing patients. Treatment planning concerns. Dent Clin North Am. 42: 1-34.

17. Montanari M, Battelli F, Callea M, Corinaldesi G, Sapigni L, et al. (2013) Oral rehabilitation with implant-supported overdenture in a child with hypohidrotic ectodermal dysplasia. Ann Oral MaxillofacSurg 1: 26.

18. Valle AL, Lorenzoni FC, Martins LM, Valle CV, Henriques JF, et al. (2011) A Multidisciplinary Approach for the Management of Hypodontia: Case Report. J Appl Oral Sci 19: 544-548.

19. Belser U, Buser D, Higginbottom F (2004) Consensus statements and recommended clinical procedures regarding esthetics in implant dentistry. Int J Oral Maxillofac Implants 19: 73-74.

20. Thilander B, Odman J, Grondahl K, Friberg B (1994) Osseointegrated implants in adolescents: A alternative in replacing missing Teeth? Eur J Orthod 16: 84-95.

21. Thilander B, Odman J, Jemt T (1999) Single implants in the upper incisor region and their relationship to the adjacent teeth. An 8-year foolw-up study. Clin Oral Implants Res 10: 346-355.

22. Thilander B, Odman J, Lekholm U (2001) Orthodontic aspects of oral implants in adolescents: A 10-year follow-up study. Eur J Orthod 23 : 715-731.

23. Thilander B, Odman J, Lekholm U (2001) Orthodontic aspects of oral implants in adolescents: A 10-year follow-up study. Eur J Orthod 23: 715-731.
24. Seymour DW, Patel M, Carter L, Chan M (2014) The Management of traumatic tooth loss with dental implants: part 2. Severe trauma. $\mathrm{Br}$ Dent J 217: 667-671.

25. Alcan T, Basa S, Kargül B (2006) Growth analysis of a patient with ectodermal dysplasia treated with endosseous implants: A 6-year follow-up. J Oral Rehabil 33: 175-182.

26. Aydinbelge M, Gumus HO, Sekerci AE, Demetoglu U, Etoz OA (2013) Implants in children with hypohidotic ectodermal dysplasia: an alternative approach to esthetic management: case report and review of the literature. Pediatr Dent 35: 441-446.

27. Bergendal B (2008) When should we extract deciduous teeth and place implants in young individuals with tooth agenesis. J Oral Rehabil 35: 55-63.

28. Bergendal T, Eckerdal O, Hallonsten AL, Koch G, Kurol J, et al. (1991) Osseointegrated implants in the oral habilitation of a boy with ectodermal dysplasia: a case report. Int Dent J 41: 149-156.

29. Heuberer S, Dvorak G, Mayer CH, Watzek G, Zechner W (2015) Dental implants are a viable alternative for compensating oligodontia in adolescents. Clin Oral Implant Res 26: 222-227.

30. Tetsch J, Tetsch P (2008) Ästhetische Resultate nach implantatprothetischen Versorgungen der Oberkieferfront. Subjektive Bewertung und fotometrische Analyse von 180 Implantat-Kronen. Implantologie 16: 371-382.

31. Tetsch J (2018) Prospektive Implantation bei Kindern und Jugendlichen. Z Zahnärztl Implantol 34: 196-204.

32. Tetsch J (2018) Prospektive Implantation nach traumatischem Frontzahnverlust beim wachsenden Patienten mit dem 5-D-Konzept. Quintessenz 69: 758-768.

33. Heuberer S, Dvorak G, Zauza K, Watzek G (2012) The use of onplants and implants in children with severe oligodontia: a retrospective evaluation. Clin Oral Implants Res 23: 827-831.

34. Yap AK, Klineberg I (2009) Dental implants in patients with ectodermal dysplasia and tooth agenesis: a critical review of the literature. Int J Prostodont 22: 268-227.

35. Klineberg I, Cameron A, Whittle T, Hobkirk J, Bergendal B, et al (2013) Rehabilitation of Children with Ectodermal Dysplasia. Part 1: An International Delphi Study. Int J Oral Maxillofac Implants 28 : 1090-1100.

36. Klineberg I, Cameron A, Whittle T, Hobkirk J, Bergendal B, et al. (2013) Rehabilitation of Children with Ectodermal Dysplasia. Part 2: An International Consensus Meeting. Int J Oral Maxillofac Implants; 28: 1101-1109.

37. Buser D, Belser U, Wismeijer D: ITI-Treatment Guide. Ästhetische Implantattherapie-Einzelzahnersatz. Quintessenz Verlag Berlin 2007. 